\title{
Overcurrent experiments on HTS tape and cable conductor
}

Tønnesen, Ole; Jensen, Kim Høj; Træholt, Chresten; Veje, Niels Erling Winsløv; Däumling (fratrådt), Manfred; Rasmussen, Claus Nygaard; Willen, D.

Published in:

IEEE Transactions on Applied Superconductivity

Link to article, DOI:

$10.1109 / 77.920130$

Publication date:

2001

Document Version

Publisher's PDF, also known as Version of record

Link back to DTU Orbit

Citation (APA):

Tønnesen, O., Jensen, K. H., Træholt, C., Veje, N. E. W., Däumling (fratrådt), M., Rasmussen, C. N., \& Willen, D. (2001). Overcurrent experiments on HTS tape and cable conductor. IEEE Transactions on Applied

Superconductivity, 11(1), 1781-1784. https://doi.org/10.1109/77.920130

\section{General rights}

Copyright and moral rights for the publications made accessible in the public portal are retained by the authors and/or other copyright owners and it is a condition of accessing publications that users recognise and abide by the legal requirements associated with these rights.

- Users may download and print one copy of any publication from the public portal for the purpose of private study or research.

- You may not further distribute the material or use it for any profit-making activity or commercial gain

- You may freely distribute the URL identifying the publication in the public portal 


\title{
Overcurrent Experiments on HTS Tape and Cable Conductor
}

\author{
Kim H. Jensen, Chresten Træholt, Erling Veje, Manfred Däumling, Claus N. Rasmussen, \\ Dag W. A. Willén and Ole Tønnesen
}

\begin{abstract}
Overcurrents in the power grid can have a magnitude of up to 20 times or higher than the rated current. This may cause problems and permanent damage to electrical equipment in the grid. High temperature superconducting (HTS) tapes are known to be sensitive to currents much larger than their critical current. In this light, it is important to investigate the response of HTS tapes and cable conductors to overcurrents several times the critical current. A number of experiments have been performed on HTS tapes and cable conductors, with currents up to 20 times the critical current. During overcurrent experiments, the voltage and the temperature were measured as functions of time in order to investigate the dynamic behavior of the HTS tape and cable conductor. After each experiment, damage to the superconductors was assessed by measuring the critical current. Preliminary results show that within seconds an HTS tape (critical current $=17 \mathrm{~A}$ ) heats above room temperature with an overcurrent larger than $140 \mathrm{~A}$. Similar overcurrent experiments showed that a HTS cable conductor could sustain damage with overcurrents exceeding 10 times the critical current of the cable conductor.
\end{abstract}

Index Terms-High Temperature Superconductors, Superconducting cable, Overcurrents

\section{INTRODUCTION}

$S^{c}$ UPERCONDUCTING cables are new electrical components that today are being designed and tested for use in the electric grid [1]-[3]. Before they can be installed in the grid they have to show reliable performance during normal load conditions and during fault conditions.

Superconducting cables are designed to fulfill a number of different criteria such as transmission capacity or nominal load current. The critical current of the superconducting cable is designed from these criteria's.

In the electrical grid there is a certain possibility that a fault can happen. This fault can be a short-circuit between individual phases or between phases and earth. The current during these short-circuits is several times larger than the nominal load current, and the faults are interrupted by the use of circuit breakers that disconnect the cable, thus interrupting the over-current. In the time from the occurrence of the shortcircuit to its removal, the superconducting cable has to

Manuscript received September 18, 2000.

K. H. Jensen, C. Traholt, E. Veje And O. Tønnesen are with the Department of Electric Power Engineering, Technical University of Denmark, Building 325, DK-2800 Lyngby, Denmark

M. Daumling, C. N. Rasmussen and D. W. A. Willen are with NKT Research, Priorparken 878, DK-2605 Brøndby, Denmark

K. H. Jensen is also with Nesa, Hagedornvej 4, 2820 Gentofte, Denmark
TABLE I DATA FOR HTS TAPE

\begin{tabular}{lc}
\hline Width & $3 \mathrm{~mm}$ \\
Thickness & $0.2 \mathrm{~mm}$ \\
Total tape length & $300 \mathrm{~mm}$ \\
BSCCO:Matrix & $1: 4$ \\
Matrix & Pure Silver \\
Critical current & $16 \mathrm{~A}$ \\
Critical current density & $106.7 \mathrm{~A} / \mathrm{mm}^{2}$ \\
\hline
\end{tabular}

sustain the short-circuit current. Because the short-circuit current can be several times larger than the nominal current, the critical current is exceeded, and the consequence can be that the superconducting cable conductor heats up, possibly above its critical temperature. A large conventional cable having a copper or aluminum conductor does not experience problems with short-circuit currents or overcurrents because of the large conductor area. A superconducting cable on the contrary will have problems as stated in [4].

In this paper how a single HTS tape behaves during a DC overcurrent (similar to the work in [5]) is investigated in section II. Damage inflicted on an HTS model cable conductor by short-circuit currents is investigated in section III by performing successive critical current measurements after the cable model has been exposed to short-circuit currents of increasing magnitude.

\section{DC OVERCURRENT MEASUREMENT ON HTS TAPE}

The HTS tape used in the overcurrent measurement was a BSSCO-2223 tape fabricated by the powder in tube technique. The particular tape used has a pure silver sheath. The tape data are shown in Table I.

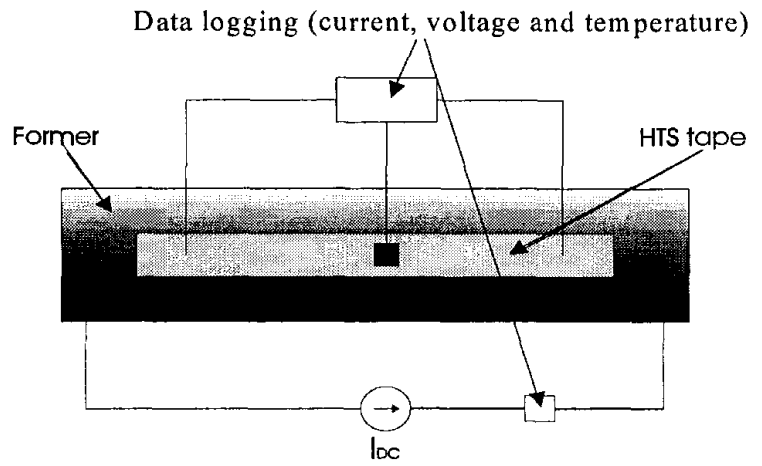

Fig. 1. Experimental set-up for HTS tape measurement 


\section{A. Experimental}

During the over-current test, the voltage, temperature and current were measured continuously using a digital oscilloscope Lecroy model LC334M. The current was supplied by an HP 6680 current source. The magnitude of the current was measured by measuring the voltage drop over a calibrated resistor. The temperature was measured by placing a silicon diode directly onto the surface of the tape. The experimental set-up for the DC overcurrent test is shown in Fig. 1. The HTS tape is cooled through a glass-fiber reinforced epoxy former (tube) that contains liquid nitrogen (LN2), which means that there is no physical contact between the tape and the LN2. The LN2 in the former is not circulated

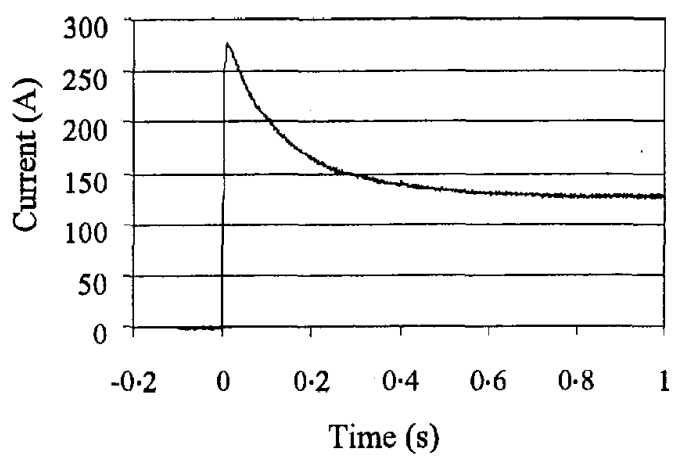

Fig. 2. Measured current as a function of time.

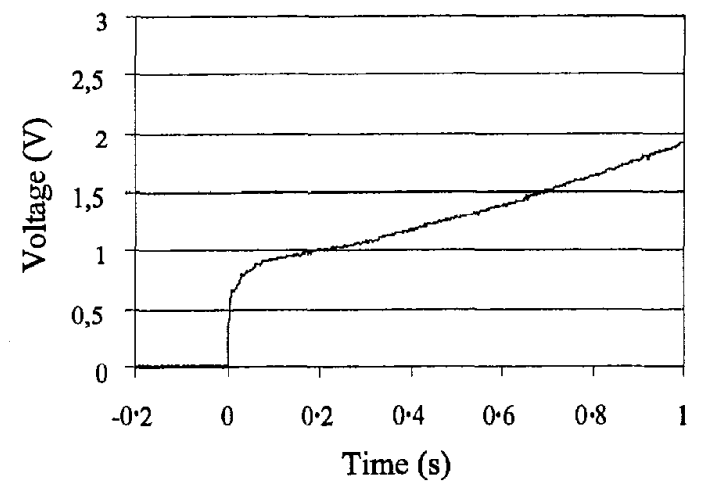

Fig. 3. Measured tape voltage as a function of time.

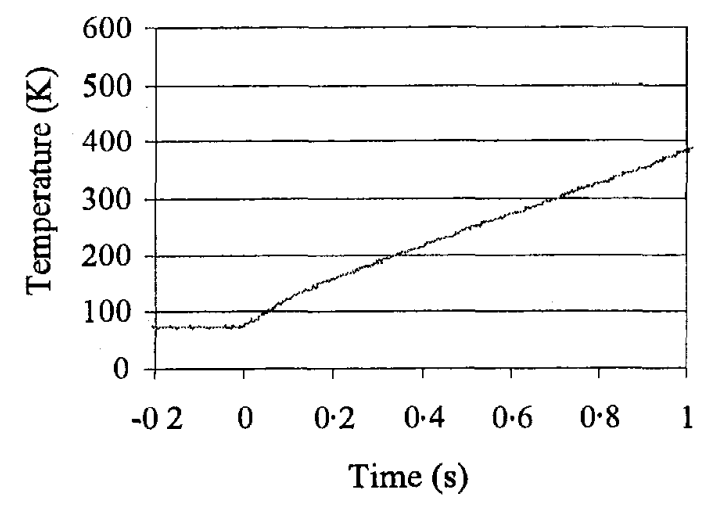

Fig. 4. Measured temperature during DC overcurrent. during the experiment. On the outside of the HTS tape and the former is placed a tube insulation, to secure good cooling of the HTS tape. This way of cooling resembles the way a room temperature dielectric HTS cable is cooled.

The voltage is measured over a $200 \mathrm{~mm}$ length of the tape and the temperature is measured at the middle of the tape. The temperature measurement is corrected for the thermal response time $t_{\text {delay }}$, of the diode by (1), [6]. The response time of a standard diode (model 471) is given in [7].

$$
T_{\text {corrected }}=T_{\text {measured }}+t_{\text {delay }} \cdot \frac{d T}{d t}
$$

$\mathrm{T}_{\text {measured }}$ is the temperature measured by the silicon diode.

\section{B. Results and Discussion}

The DC overcurrent is switched on at $t=0$ seconds and at this time the temperature is measured to be $80 \mathrm{~K}$. The high peak in the current right after switch on is due to the regulation system in the DC current source. The corresponding constant DC overcurrent with the same heat dissipation as the current shown in Fig. 2 can be calculated to be $160 \mathrm{~A}$.

After switch on the voltage and temperature of the tape rises rapidly and the temperature sensor measures a temperature of $300 \mathrm{~K}$ after 0.7 seconds. Another way of determining the temperature of the tape is by calculating its ohmic resistance from the measured voltage and current. This resistance can then be compared to a measured resistance (using 4-wire measuring technique) for the tape at room temperature $(293 \mathrm{~K})$. The calculated temperature by the resistance method gives an average over the temperature distribution along the tape. The temperature sensor on the contrary gives the temperature at a single point of the tape. The result shows that the average temperature (calculated from resistance) of the HTS tape reaches room temperature $(293 \mathrm{~K})$ after approx. 0.41 seconds. Assuming adiabatic heating of the tape, the temperature rise can also be calculated from (2).

$$
\int v(t) \cdot i(t) d t=\int V \cdot C_{p}(T) d T
$$

$v(t)$ is the measured voltage in Fig. 3 and $i(t)$ am the measured current in Fig. 2 . The specific heat $C_{p}$ for the tape is found in [8] and [9]. The time for the tape to reach room temperature $(293 \mathrm{~K})$ is calculated to be 0.36 seconds, in fair agreement with the value determined from the resistive measurement.

The difference between the two results can be explained by assuming some of the dissipated energy in the tape is transferred to the surroundings and by uncertainty in the physical parameters and constants.

The lower temperature measured by the silicon diode may be caused by its mass or not fully compensated thermal lag, but may also indicate that the temperature distribution along the HTS tape is not uniform. This could be caused by 
TABLE II

DATA FOR HTS CABLE CONDUCTORS

\begin{tabular}{lcc}
\hline & $\begin{array}{c}\text { Cable conductor used } \\
\text { in measurement series }\end{array}$ & $\begin{array}{c}\text { Cable conductor used } \\
\text { in measurement series } \\
\text { Length [m] }\end{array}$ \\
Former type & $\mathrm{A}$ & $\mathrm{B}$ \\
Number of tapes & GFRP & 1 \\
Critical current & 26 & GFRP \\
\hline
\end{tabular}

different thermal contacts from the tape to the surroundings along the tape (which is not so likely due to the closeness of the resistive and the adiabatic results) or it could come from the development of hot spots along the tape [10]. A single hot spot along the tape would only be measured by the temperature sensor if the sensor if placed in the vicinity of the hot spot. But it would always be measured by the voltage measurement.

The fast temperature rise shows that the tape is sensitive to large overcurrents, and that overcurrents of several times the cirtical current will heat the tape far above its critical temperature. If we assume that an HTS cable conductor contains 170 tapes in a number of layers (a DC critical current around $2.8 \mathrm{kA}$ ), then the overcurrent used here corresponds to a short-circuit current of $27.2 \mathrm{kA}$ in the HTS cable conductor. A short-circuit current of this size can be expected in the Danish electrical grid, but it depends on the fault location.

\section{INVESTIGATION OF DAMAGE ON HTS CABLE CONDUCTOR BY SHORT-CIRCUIT CURRENTS}

Two measurement series $\mathrm{A}$ and $\mathrm{B}$ were conducted on two 1-layer HTS cable conductors, one in each measurement series. The two HTS cable conductors where made with helically wound HTS tapes on a glass fiber reinforced polymer (GFRP) former. The data for the two cable conductors used are shown in Table II.

\section{A. Experimental}

In each measurement series the HTS cable conductor was tested with an increasing short-circuit current. The length of the short-circuit current pulse was 1 second, and the current

TABLE III

SHORT-CIRCUIT CURRENTS TESTED ON HTS CABLE CONDUCTORS

\begin{tabular}{lcc}
\hline $\begin{array}{c}\text { Number of short- } \\
\text { circuit currents }\end{array}$ & $\begin{array}{c}\text { Short-circuit currents } \\
\text { in measurement series } \\
\text { A [A] }\end{array}$ & $\begin{array}{c}\text { Short-circuit currents } \\
\text { in measurement series } \\
\text { B [A] }\end{array}$ \\
\hline 1 & 320 & 402 \\
2 & 561 & 699 \\
3 & 899 & 982 \\
4 & 1079 & 1116 \\
5 & 1263 & 1570 \\
6 & 1575 & 1818 \\
7 & 1814 & 2151 \\
8 & 2173 & 2350 \\
9 & 2363 & 2490 \\
10 & 2517 & 2793 \\
11 & 2846 & 3155 \\
12 & 3200 & \\
\hline \hline
\end{tabular}

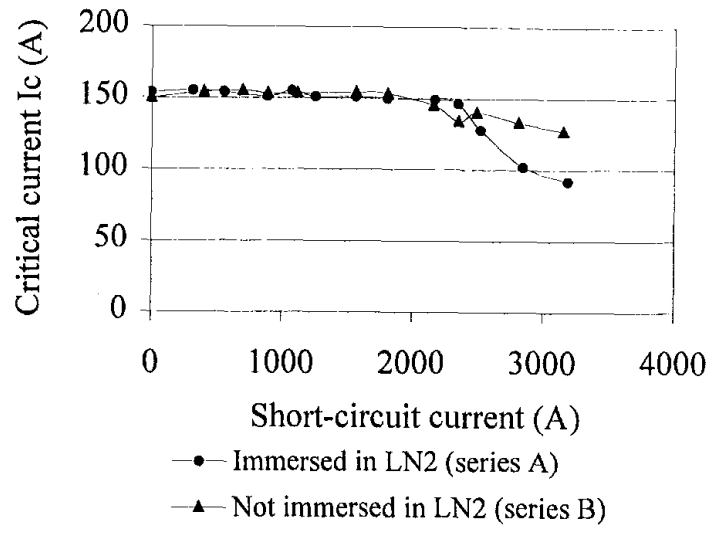

Fig. 5. Measured critical current as a function of short-circuit currents.

was $50 \mathrm{~Hz} \mathrm{AC}$ that initially contained some DC component. The short-circuit currents tested in the two measurement series can be seen in Table III; all values in Table III are rms values.

With an even current distribution among the tapes, the single tape current corresponds to $12.3 \mathrm{~A}$ at a short-circuit current of $320 \mathrm{~A}$, and to $123 \mathrm{~A}$ at a short-circuit current of 3200A rms.

After each short-circuit current, the critical current $\left(I_{c}\right)$ of the cable conductor was measured in order to monitor any possible damage that occurred to the cable conductor from the short-circuit current. The $1 \mu \mathrm{V} / \mathrm{cm}$ criterion was used to determine $I_{c}$. Further, the conductor was visually investigated for any physical damage.

In the first measurement series $A$, the HTS cable conductor was cooled by immersing it in LN2. The HTS tapes on the cable conductor were in physical contact with the LN2. In the second measurement series B, the HTS cable conductor was cooled indirectly by the former, which contained the LN2. In this case, the HTS tapes were not in physical contact with the LN2. The $\mathrm{I}_{c}$ measurements for both measurement series were performed in the same cooling manner as was the short-circuit testing. Because of the cooling procedure, the cable conductor in series $A$ was immersed in LN2 for several hours, whereas the cable conductor used in series B were not.

Cooling of the cable conductor in the two measurement series reflects how an HTS cable with cryogenic dielectric is cooled (series A) and how an HTS cable with room temperature dielectric (series B) is cooled. During the shortcircuit testing the LN2 was not circulated in the former.

\section{B. Results and Discussion}

The measured values for the critical current are seen in Fig. 5. The measurements for both series $\mathrm{A}$ and $\mathrm{B}$ show that $I_{c}$ is decreasing after large short-circuit currents. In $A$, the $I_{c}$ of the cable conductor decreases after a short-circuit current of $2350 \mathrm{~A}$, and after the maximum short-circuit current it is reduced by $40 \%$. In $B$, the decrease starts after a short-circuit current of $1814 \mathrm{~A}$. The decrease in $\mathrm{I}_{\mathrm{c}}$ is not as steep as in $\mathrm{A}$ 
and after max. short-circuit current it has decreased by $18 \%$.

The decrease in $I_{c}$ for both conductors indicates that the HTS cable conductor is damaged by a short-circuit current above $2000 \mathrm{~A}$. However, investigation of physical damage to the cable conductor between the short-circuit currents showed no signs of permanent physical damage to the tapes.

It is not known precisely how the cable conductor is damaged by the increasing short-circuit current, but a number of different aspects can be discussed.

It is known that $I_{c}$ is sensitive to mechanical forces, such as pulling, twisting and bending [10,11]. A temperature rise of the cable conductor causes the length of the tapes to increase due to thermal expansion. However, the former that the tapes are wound onto does not expand, because the heating is mostly adiabatic (see section II). If the tapes expand and the former does not, the tapes could be mechanically deformed and the $I_{c}$ lowered. After interruption of the short-circuit current the tapes are cooled down again by the coolant. The time needed for cooling after the current pulse is disrupted, is determined by the cooling method. Tapes directly immersed into LN2 would be expected to cool significantly faster than those just cooled by conduction. A physical inspection of the conductor would not necessary see this mechanically deformation, because the tapes are cooled back to the initial position before heating. Whether this fact can be used as an explanation for the different behaviour of the two cable models remains to be seen.

The magnitude of $\mathrm{dT} / \mathrm{dt}$ in the cable conductor could give rise to bubble formations in the tape and thereby lowered $I_{c}$ for the cable conductor. This would primarily be seen in measurement series A (conductor immersed in LN2). However, bubbles would be detectable by a physical investigation of the cable conductor after the short-circuit testing - no bubbles were observed.

\section{CONCLUSION}

The DC overcurrent measurements on HTS tape showed that an overcurrent of several times $I_{c}$ will heat the tape to room temperature in less than a second. This indicates that there can be problems with short-circuit currents in HTS cable conductors. A solution to this problem could be high- speed relays that interrupt the short-circuit current above a set value before it damages the conductor.

It has been shown that a one second short-circuit current with the size of several times the critical current of a HTS cable conductor can damage the conductor.

\section{ACKNOWLEDGMENT}

$\mathrm{K}$. H. Jensen thanks the high power laboratory at the Engineering College of Copenhagen for the work with the short-circuit testing in their short-circuit laboratory. The short-circuit testing was funded by the distribution companies on Zeeland, Denmark.

\section{REFERENCES}

[1] J. Rieger, M. Leghissa, J. Wiezoreck, H. -P. Kramer, G. Ries and H. W Neumuller, "Development of a $10 \mathrm{~m}$ long superconducting multistrand conductor for power transmission cables," Supercond. Sci. Technol. 1l, pp. 902-908, 1998.

[2] T. Shibata, M. Watanabe, C. Suzawa, S. Isojima, J. Fujikami, K. Sato, H. Ishii, S. Honjo and Y. Iwata, "Development of High Temperature Superconducting Power Cable Prototype System," IEEE Trans. POw. Del., vol. 14, no. 1, Jan 1999.

[3] R. Wesche, A. Anghel, B. Jakob, G. Pasztor, R. Scindler, G. Vécsey, "Design of superconducting power cables," Cryogenics, vol. 39, pp. $767-775,1999$

[4] O. Tønnesen, S. Hansen, P. Jørgensen, K. Lomholt, S. D.Mikkelsen, J. Okholm, S. Salvin and J. J. Østergaard, "Power application for superconducting cables" Applied Superconductivity 1999, vol. 1, pp. 1103-1109.

[5] L. L. Lay, D. M. Spiller and O. Belmont, "Over critical-current behaviour of bi-2223 tapes," IEEE Trans. App. Supercond. Vol. 9, no. 2, June 1999.

[6] B. Lawton and G Klingenberg, Transient temperature in engineering and science, Oxford University Press, 1996.

[7] Lakeshore, Temperature measurement and control catalogue 2000.

[8] J. L. Parish, "Heat Capacity of HTSC at temperatures above $\mathrm{T}_{c}$," phys. stat. sol., vol. 182 , pp. 399-410, 1994.

[9] F. P. Incropera and D. P. Dewitt, Introduction to heat transfer, 3rd ed., J. Wiley \& Sons, 1996.

[10] S. B. Kim, A. Ishiyamat, H. Okada and S. Nomura, "Normal-zone propagation properties in $\mathrm{Bi}-2223 / \mathrm{Ag}$ superconducting multifilament tapes," Cryogenics, vol. 38, no. 8, pp. 823-831, 1998.

[11] P. S. Hansen, Z. Han and J. I. Bech, "Stresses and strains in multifilament hts tapes," IEEE Trans. App. Supercond. Vol. 9, no. 2, June 1999.

[12] P. Vase, R. Flukiger, M. Leghissa and B. Glowacki, "Current status of high-T ${ }_{c}$ wire," Supercond. Sci. Technol. 13, pp. R71-R84, 2000. 